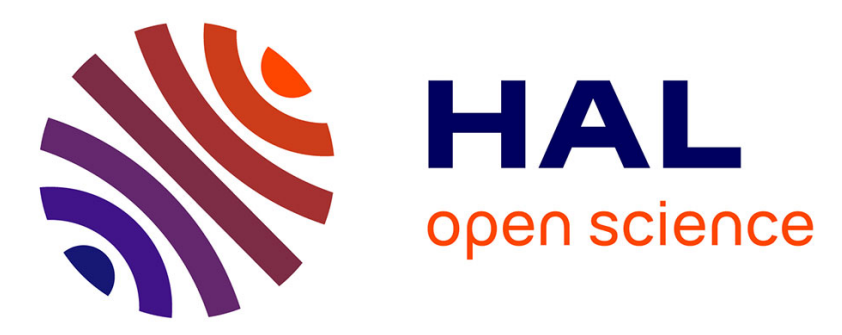

\title{
Climatic microrefugia under anthropogenic climate change: implications for species redistribution
} Jonathan Roger Michel Henri Lenoir, Tarek Hattab, Guillaume Pierre

\section{To cite this version:}

Jonathan Roger Michel Henri Lenoir, Tarek Hattab, Guillaume Pierre. Climatic microrefugia under anthropogenic climate change: implications for species redistribution. Ecography, 2016, 40, pp.253 266. 10.1111/ecog.02788 . hal-03276591

\section{HAL Id: hal-03276591 \\ https://hal.science/hal-03276591}

Submitted on 2 Jul 2021

HAL is a multi-disciplinary open access archive for the deposit and dissemination of scientific research documents, whether they are published or not. The documents may come from teaching and research institutions in France or abroad, or from public or private research centers.
L'archive ouverte pluridisciplinaire HAL, est destinée au dépôt et à la diffusion de documents scientifiques de niveau recherche, publiés ou non, émanant des établissements d'enseignement et de recherche français ou étrangers, des laboratoires publics ou privés. 
Ecography 40: 253-266, 2017

doi: $10.1111 /$ ecog. 02788

(C) 2016 The Authors. Ecography (C) 2016 Nordic Society Oikos

Subject Editor: Catherine Graham. Editor-in-Chief: Miguel Araújo. Accepted 1 November 2016

\title{
Climatic microrefugia under anthropogenic climate change: implications for species redistribution
}

\author{
Jonathan Lenoir*, Tarek Hattab* and Guillaume Pierre
}

J. Lenoir (jonathan.lenoir@u-picardie.fr) and T. Hattab, Unité de Recherche 'Ecologie et Dynamique des Systèmes Anthropisés' (EDYSAN, FRE 3498 CNRS-UPJV), Université de Picardie Jules Verne, 1 rue des Louvels, FR-80037 Amiens Cedex 1, France. - G. Pierre, Groupe d'Etude des Géomatériaux et Environnements Naturels, Anthropiques et Archéologiques (GEGENA2, EA 3795), Université de Reims Champagne-Ardenne, 57 rue Pierre Taittinger, FR-51096 Reims Cedex, France.

\begin{abstract}
The role of modern climatic microrefugia is a neglected aspect in the study of biotic responses to anthropogenic climate change. Current projections of species redistribution at continental extent are based on climatic grids of coarse $(\geq 1$ $\mathrm{km}$ ) resolutions that fail to capture spatiotemporal dynamics associated with climatic microrefugia. Here, we review recent methods to model the climatic component of potential microrefugia and highlight research gaps in accounting for the buffering capacity due to biophysical processes operating at very fine $(<1 \mathrm{~m})$ resolutions (e.g. canopy cover) and the associated microclimatic stability over time (i.e. decoupling). To overcome this challenge, we propose a spatially hierarchical downscaling framework combining a free-air temperature grid at $1 \mathrm{~km}$ resolution, a digital elevation model at $25 \mathrm{~m}$ resolution and small-footprint light detection-and-ranging (LiDAR) data at $50 \mathrm{~cm}$ resolution with knowledge from the literature to mechanistically model sub-canopy temperatures and account for microclimatic decoupling. We applied this framework on a virtual sub-canopy species and simulated the impact of a warming scenario on its potential distribution. Modelling sub-canopy temperatures at $50 \mathrm{~cm}$ resolution and accounting for microclimatic stability over time enlarges the range of temperature conditions towards the cold end of the gradient, mitigates regional temperature changes and decreases extirpation risks. Incorporating these spatiotemporal dynamics into species redistribution models, being correlative, mechanistic or hybrid, will increase the probability of local persistence, which has important consequences in the understanding of the capacity of species to adapt. We finally provide a synthesis on additional ways that the field could move towards effectively considering potential climatic microrefugia for species redistribution.
\end{abstract}

Anthropogenically-driven global changes such as biological invasions, land use and more recently climate warming have been recognized as the main determinants triggering the erosion of biodiversity during the so-called 6th mass extinction event (Barnosky et al. 2011). If climate warming exceeds species' thermal tolerances, species may track (cf. climate-induced range shifts) (Lenoir et al. 2008, Lenoir and Svenning 2015) or adapt to (cf. climatic niche shifts through acclimation or microevolutionary processes) (Wasof et al. 2013, 2015) the modified regional climate to avoid extinction, two processes being non-mutually exclusive throughout a species range (Davis and Shaw 2001). However, recent findings suggest that the realized climatic niche of species may be stable over time (Wasof et al. 2015) and that the magnitude of observed species range shifts is lower than expected under the assumption of synchronous response to climate change (Lenoir and Svenning 2013). This disequilibrium with climate not only suggests dispersal and establishment lags but also extirpation lags through local persistence (Svenning and Sandel 2013, Lenoir and

$\left(^{*}\right)$ These authors contributed equally to this paper.
Svenning 2015, Bertrand et al. 2016). For instance, living organisms may find long-term enclaves/shelters, where specific and relatively stable climatic conditions are buffered and thus decoupled from regional climate change, to persist locally as climate relicts (Hampe and Jump 2011). Such peculiar microclimates that support isolated populations of organisms over long time periods (several generations) outside their main distribution area refer to climatic microrefugia (sensu Rull 2009, Dobrowski 2011, Hannah et al. 2014, Hylander et al. 2015) and are thus particularly relevant to explain disequilibrium dynamics under climate change.

Microrefugia (plural) and microrefugium (singular) are terms initially coined by paleoecologists (Leal 2001, Rull 2009) to designate one or several small area(s) sheltered from broader-scale environmental instabilities over time, in which small populations of organisms can survive outside their main distribution area (i.e. the macrorefugium). Famous examples are the remote or distal microrefugia (Rull 2009, 2010) - also known as cryptic refugia when specifically referring to the contraction phase of a species' expansion-contraction cycle (Stewart and Lister 2001, Stewart et al. 2010) - located close to the Scandinavian ice sheet and very far from macrorefugium located in southern 
Europe during the Last Glacial Maximum (Parducci et al. 2012). Because contemporary and future climate changes are differing too much from past climate changes, we cannot rely on Pleistocene climatic microrefugia solely to identify potential modern climatic microrefugia (Keppel et al. 2015). However, the concept of climatic microrefugia and its associated microclimate is still useful and is now a hot topic of ongoing research and discussion (Hannah et al. 2014, Keppel and Wardell-Johnson 2015). Yet, the role of microclimate in shaping species distribution under modern climate change is at best underestimated but most of the time overlooked (Potter et al. 2013). We urgently need to understand and quantify the role of microclimate in explaining disequilibrium dynamics, especially so in lowland ecosystems where biotic responses are lagging even more than in mountainous ecosystems (Bertrand et al. 2011, 2016).

To model species redistribution under anthropogenic climate change, numerous studies have been using temperature grids of coarse $(\geq 1 \mathrm{~km})$ resolutions, either interpolated from weather stations like WorldClim grids (Hijmans et al. 2005) or simulated by global and regional climate models. Such coarse-grained temperature grids represent free-air or synoptic temperature and thus fail to capture surface temperature generated by topographic (cf. physiographic processes) or habitat (cf. biophysical processes) features that decouple upper atmospheric conditions from boundary layer effects (Geiger 1950, Grotch and MacCracken 1991, Barry 1992,
Chen et al. 1999, Pepin and Seidel 2005), which is the climatic basis for microrefugia (Dobrowski 2011). Therefore, if we aim at accounting for the role of potential climatic microrefugia in shaping the spatial distribution of species under anthropogenic climate change, we need modelling approaches based on fine-grained climatic data to capture thermal variability that can reach up to $6.6^{\circ} \mathrm{C}$, depending on the topographic heterogeneity, within $1 \mathrm{~km}$ spatial units (Lenoir et al. 2013). The recent literature proposes several approaches chiefly based on physiographically informed models to downscale macroclimate or interpolate topoclimate at fine $(30 \mathrm{~m})$ resolutions (Ashcroft et al. 2008, 2012, Dobrowski 2011, Dingman et al. 2013, McCullough et al. 2016), with the goal of using these fine-grained topoclimatic grids as predictor variables to model potential climatic microrefugia (McCullough et al. 2016). Although such models have been recently used to improve species redistribution projections (Ashcroft et al. 2008, Dobrowski 2011, Franklin et al. 2013, Slavich et al. 2014), we argue that one key component of what defines a potential climatic microrefugium is still missing: climatic stability over time (Ashcroft et al. 2012, Gollan et al. 2014, Heller et al. 2015). Climatic stability is the process by which local interior climatic (i.e. microclimate) conditions within a microrefugium are decoupled from regional exterior climatic (i.e. macroclimate) fluctuations over time - both intra- and inter-annually - (Keppel et al. 2015) (Fig. 1). To support our claim, we here provide

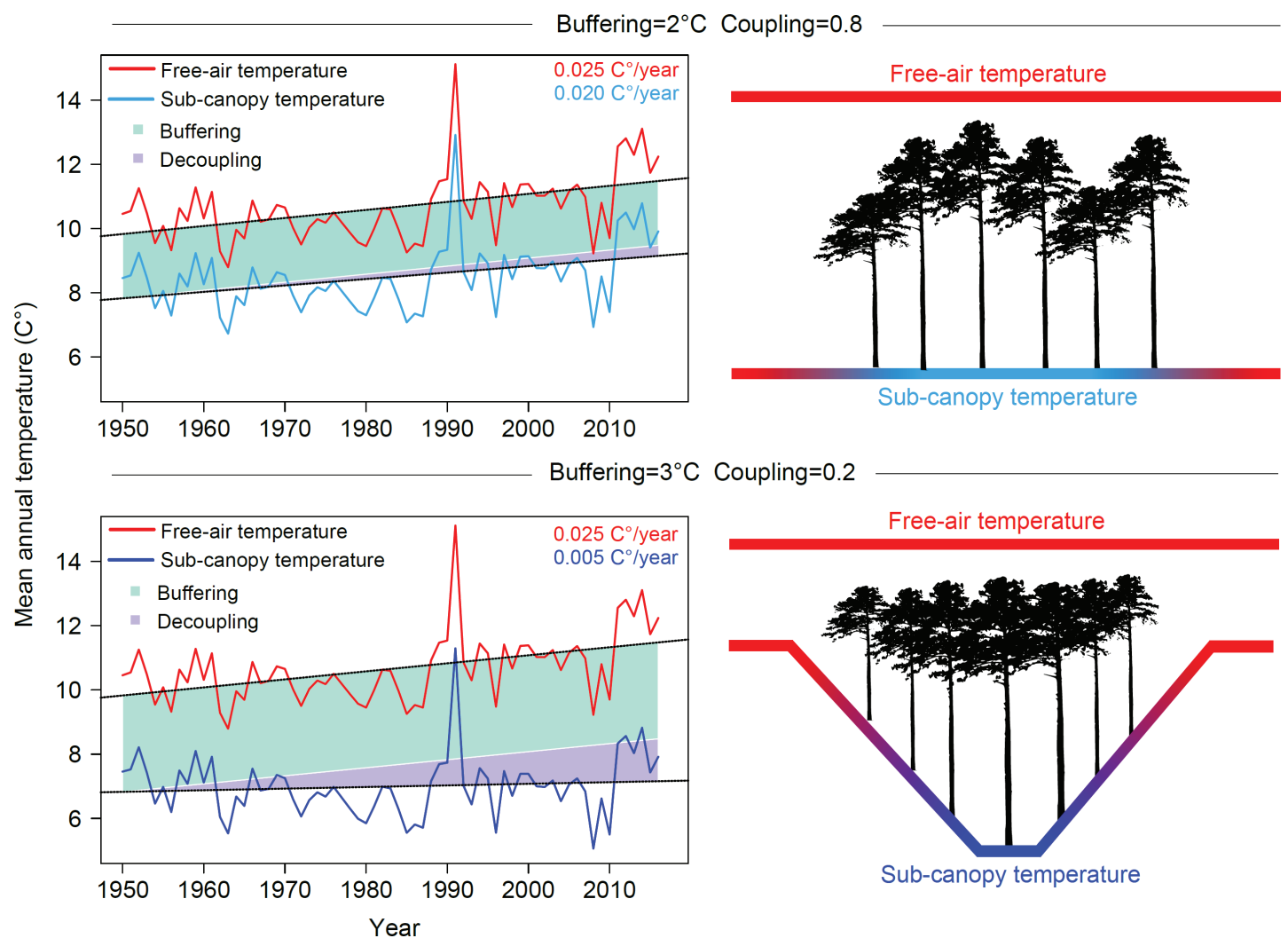

Figure 1. Conceptual diagram illustrating the buffering (cf. magnitude of the difference between the intercept values of the two regression lines for sub-canopy and free-air temperatures) and decoupling (cf. the magnitude of the difference between the slope parameters of the two regression lines for sub-canopy and free-air temperatures) capacities associated with microrefugia. Top panel shows the buffering and decoupling capacities due to canopy cover solely whereas the bottom panel shows the buffering and decoupling capacities due to the combined effect of canopy cover and topographic concavity. 
an overview of the most recent methods used in the scientific literature to model the climatic component of potential microrefugia, discuss some of the challenges associated with these modelling attempts and propose one way to appropriately address these challenges through a hierarchical downscaling framework. Importantly, our framework is not only valid for purely correlative species redistribution models but also for mechanistic (i.e. process-based) (Kearney and Porter 2009) or hybrid (Dullinger et al. 2012) models. We finally provide a broader perspective on additional ways that the field could move towards effectively considering potential climatic microrefugia under anthropogenic climate change.

\section{A general view on the most recent methods used to model the climate of potential microrefugia under anthropogenic climate change}

We searched the 'Web of Science Core Collection' in ISI Web of Science for articles and reviews published in English between 1900 to 2016 with the keywords "microrefugi*" and "climate change" or "climate warming" in the title, abstract or keywords. We used the very specific "microrefugi*” keyword and not the more general "refugi*" keyword because a general review on refugia under climate change already exists (Keppel et al. 2012). Besides, studies using the prefix "micro" are more likely to be relevant for establishing the status of the most recent methods that are used in the scientific literature to model the microclimatic component of potential microrefugia. This resulted in 54 relevant references, all published between 2009 and 2016 (70\% since 2014). Hence, research on microrefugia under anthropogenic climate change is an emerging scientific field. We screened each abstract to select the studies that propose methods to model the climatic components of potential modern microrefugia at fine $(<50 \mathrm{~m})$ resolution. Studies focusing on glacial microrefugia solely $(n=19)$ or potential modern microrefugia but without directly modelling microclimate (Schut et al. 2014, Suggitt et al. 2015, Keppel et al. 2015, Thapa et al. 2016, Wilkin et al. 2016) or at a resolution coarser than 50 m (Miró Pérez et al. 2015) were excluded. We chose a cut-off value of $50 \mathrm{~m}$ because coarser spatial resolutions are unlikely to capture microclimate (Potter et al. 2013). Of these 54 references, seven fitted our criteria for selection. To expand our literature search, we screened the reference lists in each of these seven publications for relevant studies and searched Google Scholar until June 2016 to check the most recently published literature fitting our selection criteria.

In total, we found 15 studies proposing methods to model the climatic components of potential modern microrefugia at fine $(<50 \mathrm{~m})$ spatial resolution (Table 1$)$. Hitherto, three mainstream approaches have been suggested in the recent literature: 1) spatial interpolations based on local field measurements from microsensors (cf. microclimate) (Ashcroft et al. 2012); 2) downscaling techniques based on synoptic weather stations (cf. macroclimate), macroclimatic grids or a combination of both (McCullough et al. 2016); and 3) mechanistic models (Bennie et al. 2008). Whatever the overall approach used (interpolating microclimate or downscaling macroclimate), all the recent literature rely on topographic variables derived from fine-grained $(<50 \mathrm{~m})$ digital elevation models (DEMs) to capture the climatic basis for potential microrefugia (Table 1). Indeed, elevation is widely acknowledged as one of the most influential variables to model microclimate (Vanwalleghem and Meentemeyer 2009, Ashcroft and Gollan 2013, Frey et al. 2016). However, it has been demonstrated that downscaling

Table 1. List of recent publications proposing new methods to model the climatic basis for potential microrefugia under anthropogenic climate change. CDI refers to the type of climatic data input (macroclimatic or microclimatic) used to model the climatic basis of potential modern microrefugia and usually obtained from: weather stations (WS); macroclimatic grids (MG); or microsensors (MS). RV is the list of response variables used in the models: temperature (T); humidity (Hum); evapotranspiration (ET); or climatic water deficit (CWD). PV gives the list of predictor variables used in the models: topographic (Topo); biotic (Bio); or hydrologic (Hydro). MM is the modelling method used: interpolation of microclimatic input data (I); downscaling of macroclimatic input data (D); or mechanistic (M). RS specifies whether airborne remote sensing data (e.g. LiDAR or hyperspectral images) have been used to derive topographic as well as biotic predictor variables. CS shows whether climatic stability over time has been accounted for in the models. SDM tells whether models' outputs have been used as predictor variables in species distribution models. SE and SR are the spatial extent and resolution of the study, respectively.

\begin{tabular}{|c|c|c|c|c|c|c|c|c|c|}
\hline Ref. ID & CDI & RV & PV & MM & RS & $\mathrm{CS}$ & SDM & $\mathrm{SE}\left(\mathrm{km}^{2}\right)$ & $\mathrm{SR}(\mathrm{m})$ \\
\hline 1 & MS & $\mathrm{T}$ & Topo+ Bio & I & No & Yes & No & 60000 & 25 \\
\hline 2 & MS & $\mathrm{T}+\mathrm{Hum}$ & Topo + Bio & I & No & No & No & 60000 & 25 \\
\hline 3 & MS & $\mathrm{T}+\mathrm{Hum}$ & Topo + Bio & I & No & No & No & 150000 & 25 \\
\hline 4 & $\mathrm{WS}+\mathrm{MS}$ & $\mathrm{T}+\mathrm{ET}$ & Торо & M & Yes & No & No & 2 & 5 \\
\hline 5 & WS + MS & $\mathrm{T}+\mathrm{ET}$ & Tоро & M & Yes & No & Yes & 20000 & 5 \\
\hline 6 & $M G+M S$ & $\mathrm{~T}$ & Topo & $\mathrm{D}$ & No & No & Yes & 16 & 30 \\
\hline 7 & $\mathrm{WS}+\mathrm{MG}$ & $\mathrm{T}+\mathrm{CWD}$ & Topo & I & No & No & Yes & 2752 & 30 \\
\hline 8 & MS & $\mathrm{T}$ & Topo + Bio & I & Yes & No & No & 64 & 5 \\
\hline 9 & $\mathrm{WS}+\mathrm{MS}$ & $\mathrm{T}$ & Tоро & I & No & No & No & 2090 & 30 \\
\hline 10 & MS & $\mathrm{T}$ & Topo + Bio & I & No & Yes & No & 60000 & 25 \\
\hline 11 & MG & $\mathrm{T}+\mathrm{CWD}$ & Topo+ Hydro & D & No & No & No & 330 & 30 \\
\hline 12 & MG & $T+C W D$ & Topo+ Hydro & $\mathrm{D}$ & No & Yes & No & 330 & 30 \\
\hline 13 & MS & $\mathrm{T}$ & Topo & I & Yes & No & Yes & 700 & 2 \\
\hline 14 & MS & $\mathrm{T}$ & Topo + Bio & I & No & No & Yes & 60000 & 25 \\
\hline 15 & MS & $\mathrm{T}$ & Topo + Bio & I & Yes & No & No & 274 & 10 \\
\hline
\end{tabular}

${ }^{1}$ Ashcroft et al. (2012); ${ }^{2}$ Ashcroft and Gollan (2012); ${ }^{3}$ Ashcroft and Gollan (2013); ${ }^{4}$ Bennie et al. (2008); ${ }^{5}$ Bennie et al. (2013); ${ }^{6}$ Dingman et al. (2013); ${ }^{7}$ Dobrowski (2011); ${ }^{8}$ Frey et al. (2016); ${ }^{9}$ Fridley (2009); ${ }^{10}$ Gollan et al. (2014); ${ }^{11}$ Hannah et al. (2014); ${ }^{12}$ McCullough et al. (2016); ${ }^{13}$ Pradervand et al. (2014); ${ }^{14}$ Slavich et al. (2014); ${ }^{15}$ Vanwalleghem and Meentemeyer (2009). 
free-air temperatures from synoptic weather stations at fine $(30 \mathrm{~m})$ resolution using elevation-based lapse rates only is not enough to capture potential microrefugia but that topoclimate (e.g. cold-air drainage, solar insolation, surface flow) needs to be modelled too (Dobrowski et al. 2009, Dobrowski 2011). By using a physiographically informed model accounting for cold-air drainage effects, Dobrowski (2011) has increased the probability that red fir (Abies magnifica) will persist within potential microrefugia under climate warming scenarios of $+2^{\circ} \mathrm{C}$ to $+4^{\circ} \mathrm{C}$ compared with a simple downscaling approach at the same resolution but based on elevation-based lapse rates solely. Accordingly, Ashcroft and Gollan (2013) have demonstrated that physiographic variables, such as topographic exposure and distance to the coast, derived from a $25 \mathrm{~m}$ DEM, matter more than elevation to interpolate daily maximum air temperature at $5 \mathrm{~cm}$ height from a network of microsensors. Using the same $25 \mathrm{~m}$ resolution grid of daily maximum air temperature at $5 \mathrm{~cm}$ height as a predictor variable in fine-grained redistribution models for 295 species of grasses and ferns across a $60000 \mathrm{~km}^{2}$ coastal region in Australia, Slavich et al. (2014) have projected an $18 \%$ decrease in the number of species becoming critically endangered under future climate change. Although this spatial resolution is fine enough to capture topoclimate in mountainous regions (Fridley 2009, Dobrowski 2011), this is unfortunately too coarse to capture the biophysical processes (e.g. canopy cover) related to climatic buffering (De Frenne et al. 2013, Frey et al. 2016) and its associated decoupling over time, which matter for modelling potential microrefugia (Keppel et al. 2012). To address this issue, remote sensing techniques such as light detectionand-ranging (LiDAR) sensors as well as hyperspectral images are very powerful and promising tools. Small-footprint LiDAR provides an extremely high-resolution analysis of the $3 \mathrm{D}$ canopy structure and height of the vegetation and the ground surface (Lefsky et al. 2002), thus providing structural properties of the landscape. Although LiDAR tools have clearly been highlighted as the way forward to unlock the technical limitations to describe and assess physiographic and biophysical processes related to microrefugia (Keppel et al. 2012), their use for modelling potential microrefugia is largely underexplored by ecologists. Very few studies have used LiDAR or multispectral aircraft imagery in combination with climatic data to capture fine-grained biophysical processes associated with microrefugia (Vanwalleghem and Meentemeyer 2009, Frey et al. 2016), but none used it to project species distribution changes.

Finally, the refugial capacity of a microrefugium depends on whether a given population can persist for a limited period of time under global climate change (cf. a holdout) or until regional climatic conditions are favourable again (cf. an effective microrefugium) (Hannah et al. 2014, Keppel et al. 2015). Both holdouts and effective microrefugia suggest the survival of several generations, implying long periods ranging from decades to millennia. Such a time scale is what distinguishes potential climatic microrefugia from ephemeral climatic microrefuges (cf. small areas sheltered from seasonal or short-term climatic fluctuations occurring over the life span of an organism) (Gollan et al. 2014). Thus, climatic stability here not only involves cooler and milder local interior conditions ( $\mathrm{cf}$. smaller range of variation) than regional exte- rior conditions during summer/day- and winter/night-time (cf. intra-annual stability), respectively (Chen et al. 1999, Joly 2014), but most importantly a weak coupling between interior and regional exterior inter-annual climatic fluctuations (Dobrowski 2011, Pepin et al. 2011) (Fig. 1). Although topographically heterogeneous and/or forested areas are likely to be climatically more decoupled, and thus stable, than topographically homogeneous and/or open areas (Heller et al. 2015) (Fig. 1), modelling the climatic stability inherent to microrefugia is still a challenge. Only three studies so far accounted for climatic stability over time when modelling potential microrefugia under climate change (Ashcroft et al. 2012, Gollan et al. 2014, McCullough et al. 2016). For example, Ashcroft et al. (2012) produced a refugia index (RI) that specifically incorporates both intra- and inter-annual climatic variability on a continuous gradient. However, none of these studies tested the impact of the inter-annual climatic stability of microrefugia for species redistribution. Yet, the greater the degree of inter-annual local climate decoupling, the greater the chances for a given population to locally persist over long time periods (Dobrowski 2011, Hampe and Jump 2011), thus increasing the probability for a potential microrefugium to be effective under climate change (Keppel et al. 2015). We assume that accounting for the inter-annual local climate decoupling associated with the buffering effect of microrefugia is likely to further increase the probability of species persistence under future climate warming.

\section{A spatially hierarchical downscaling framework to account for both fine-grained biophysical processes and climatic stability over time}

To illustrate our framework, we created a virtual sub-canopy species (hereafter Polystichum virtualis) unlimited by dispersal whose distribution is boreal and whose southern range margin in Europe occurs outside the matrix (cf. northern latitudes) in mountain forests in southern France as well as in lowland forests in northern France, including the forest of Compiègne (Supplementary material Appendix A1). For the sake of simplicity, we used maximum temperature of the warmest month $(B I O 5)$ as the only climatic determinant of the spatial distribution of $P$. virtualis. BIO5 belongs to the set of physiologically most relevant bioclimatic determinants of spatial distribution for a wide range of taxanomic groups (Rödder et al. 2009, Porfirio et al. 2014, Distler et al. 2015). $\mathrm{BIO5}$ is also the climatic variable that best represents maximum daily air temperatures during the growing season, a key variable used in microclimate studies to assess the buffering effect due to both topographic (e.g. ravines) and habitat (e.g. trees) features (Xu et al. 1997, Chen et al. 1999, Grimmond et al. 2000, Renaud and Rebetez 2009, Locosselli et al. 2016). Although simplistic, this virtual species based on a uni-dimensional climatic niche, i.e. its fundamental niche, and further filtered by forest habitats, i.e. its realized niche, will allow us to better illustrate the mechanics of our downscaling framework that can be decomposed into three main steps. First, we modelled topoclimate at fine $(25 \mathrm{~m})$ resolution from free-air temperature grids using a statistical downscaling approach based on a physiographically informed model. Then, we used topographic concavity and canopy 
density derived from LiDAR data as well as knowledge from the literature to mechanistically model sub-canopy temperatures and incorporate the buffering capacity operating at very fine $(50 \mathrm{~cm})$ resolution before projecting the probability of occurrence of $P$. virtualis at time $t$. Finally, we added the difference $\left(\triangle T^{\circ} C\right)$ between future and current free-air temperatures to current sub-canopy temperatures weighted by the degree of local decoupling between sub-canopy and freeair temperatures to mechanistically account for the relative climatic stability of potential microrefugia before projecting the probability of occurrence of $P$. virtualis at time $t+d t$. Below is a more detailed description of our downscaling framework.

\section{Statistical downscaling of free-air temperature at $25 \mathrm{~m}$ resolution to model topoclimate}

We first downloaded $B I O 5$ at $1 \mathrm{~km}$ resolution from WorldClim (<www.worldclim.org/>, Hijmans et al. 2005). This temperature grid representing free-air temperature conditions was then statistically downscaled at $25 \mathrm{~m}$ resolution across a climatically homogeneous region in northern France using a physiographically informed geographically weighted regression (GWR) model (Fotheringham et al. 2002) (Supplementary material Appendix A2). In short, GWR extends the traditional regression approach by allowing estimated regression parameters to vary across space. Therefore, GWR models are particularly relevant to explore the scale-dependent and spatially non-stationary relationships between free-air temperatures and physiographic variables (Su et al. 2012) and have been successfully used in several research fields (Li et al. 2010, Wang et al. 2011, Tian et al. 2012). As predictor variables, we used the same set of physiographic descriptors selected in many studies modelling topoclimate at 10 to $30 \mathrm{~m}$ resolution (Fridley 2009, Vanwalleghem and Meentemeyer 2009, Dobrowski 2011, Ashcroft et al. 2012): altitude; slope; eastness; northness; distance to the coast; monthly average daily clear-sky insolation time; and land cover (Supplementary material Appendix A2). Our GWR model performed very well across northern France (quasi-global adjusted $\mathrm{R}^{2}=0.99$ ) and also within the forest of Compiègne (mean local adjusted $\mathrm{R}^{2}=0.85$; standard error of the mean local adjusted $\mathrm{R}^{2}= \pm 0.2410^{-4}$ ) (Supplementary material Appendix A2). Although GWR is a very powerful tool for downscaling macroclimate at finer spatial resolutions, none of the recent studies modelling potential microrefugia under anthropogenic climate change (cf. Table 1) has considered it. We here advocate for a more extensive use of GWR in microclimate studies.

\section{Mechanistic downscaling of topoclimate at $50 \mathrm{~cm}$ resolution to model sub-canopy temperatures}

To downscale topoclimate at a resolution finer than $25 \mathrm{~m}$, not only physiographic but also biophysical processes need to be modelled. Airborne LiDAR data were acquired at 50 $\mathrm{cm}$ resolution across the entire lowland forest of Compiègne $\left(144 \mathrm{~km}^{2}\right)$ (Source: Office National des Forêts) to achieve this aim (Supplementary material Appendix A3). To first account for the climatic buffering effect provided by topographic features (cf. physiographic processes) such as small ravines and gullies not already captured by the $25 \mathrm{~m}$ topoclimatic model, we generated a map of relative topographic concavity that we scaled to range between 0 and 1 (Supplementary material Appendix A3). Thus, the deepest and narrowest ravine within the forest of Compiègne has a topographic concavity value equal to 1 and hence is the most likely to provide conditions for the formation of a shallow and cooler air layer near the ground (i.e. cold-air drainage effects) likely buffered from the warmer regional climate (Dobrowski 2011). For instance, within a mid-latitude secondary growth deciduous forest in south central Indiana (USA), spatial differences between ravines and flat terrains in daily maximum air temperature range from 0.5 to $4.1^{\circ} \mathrm{C}$ (average of $2^{\circ} \mathrm{C}$ ) (Grimmond et al. 2000).

Additionally, to account for the climatic buffering effect provided by habitat features (cf. biophysical processes) such as trees and tall shrubs, we generated a map of canopy density (Supplementary material Appendix A3). Canopy density is an important driver that buffers well-mixed above-canopy air temperatures at very fine $(<1 \mathrm{~m})$ resolutions through cooler sub-canopy temperatures during summer/day-time but warmer sub-canopy temperatures during winter/nighttime (Chen et al. 1999, Fridley 2009, Joly 2014). For instance, the protective influence of forest canopy in temperate ecosystems can provide sub-canopy temperatures about $2^{\circ} \mathrm{C}$ cooler, on average, than free-air temperatures during summer time (Chen et al. 1999, Fridley 2009).

Before mechanistically transforming synoptic temperatures at $25 \mathrm{~m}$ resolution to sub-canopy temperatures at 50 $\mathrm{cm}$ resolution using LiDAR data, we reviewed the scientific literature to assess the buffering effects provided by both topographic and habitat features (Supplementary material Appendix A4). We used an approach similar to Scheffers et al. (2014) who reviewed microhabitat-buffering effects for the tropics. Based on knowledge from the scientific literature focusing on temperate deciduous forests (Table A4-1 in Supplementary material Appendix A4), we found that maximum air temperature during summer time can be reduced, on average ( \pm the standard error of the mean), by $3.2^{\circ} \mathrm{C}$ $( \pm 0.25 ; n=23)$. Hence, we propose to illustrate the impact of the climatic buffering effect on sub-canopy temperature by setting a maximum of $3^{\circ} \mathrm{C}$ reduction in $\mathrm{BIO} 5$ due to the combined effect of topographic concavity $\left(-1^{\circ} \mathrm{C}\right)$ and canopy density $\left(-2^{\circ} \mathrm{C}\right)$ (see Supplementary material Appendix A4 for further justifications). We also assumed that the buffering capacity increases linearly with topographic concavity and canopy density, without any interaction term (Fig. 2). Using the topographic concavity and canopy density grids available at $50 \mathrm{~cm}$ resolution across the forest of Compiègne (Supplementary material Appendix A3) and applying this linear transformation (Fig. 2) to our topoclimate model at $25 \mathrm{~m}$ resolution (Supplementary material Appendix A2), we mechanistically modelled sub-canopy temperatures at $50 \mathrm{~cm}$ resolution across the entire forest.

\section{Accounting for local decoupling between sub-canopy and free-air temperatures}

The buffering capacity provided by concave topographic features and canopy density also implies stable microclimatic conditions from year to year through a local decoupling between microclimate and macroclimate. Although such a decoupling effect cannot completely isolate interior climatic conditions from regional exterior climatic fluctuations, it 


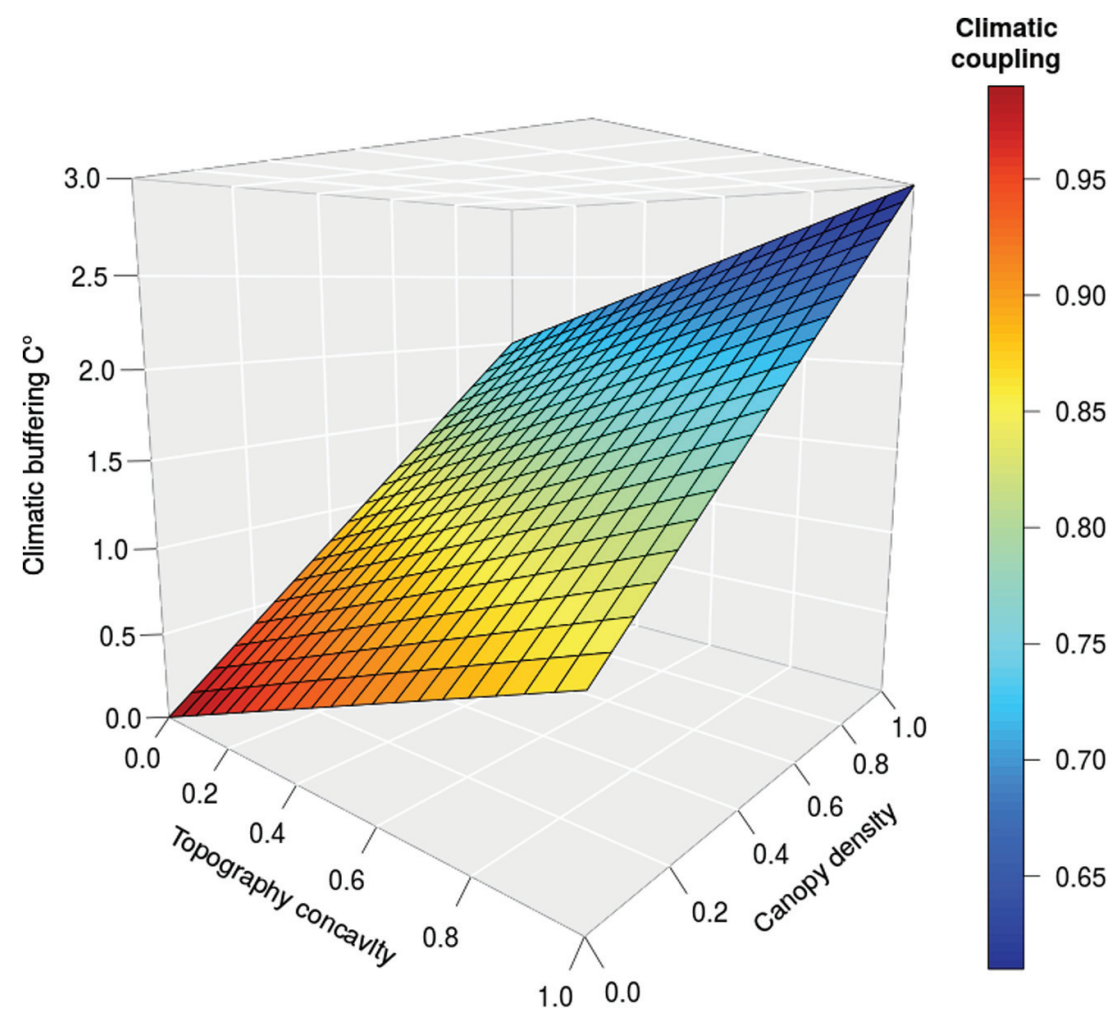

Figure 2. Model of sub-canopy temperature conditions accounting for both the buffering capacity and the local decoupling due to topographic concavity and canopy density.

does reduce the impact of regional climatic warming (Fig. 1). For instance, Pepin et al. (2011) have already demonstrated that climate warming is weaker at decoupled locations compared with exposed locations in the western United States.

The degree of local decoupling can be assessed from time series by computing the slope parameter between microhabitat (e.g. sub-canopy) and macrohabitat (e.g. free-air) temperatures, being the response and explanatory variables, respectively, in an ordinary least-square (OLS) regression (Ewers and Banks-Leite 2013, Varner and Dearing 2014, Locosselli et al. 2016). A slope value close to one corresponds to a high coupling whereas a slope value close to zero corresponds to a high decoupling. For instance, Locosselli et al. (2016) found a coupling of 0.6 between in-situ (within concave topographic features) and free-air maximum temperatures during summer 2013 in Brazil. Similarly, in a tropical forest in Brazil, Ewers and Banks-Leite (2013) used one year of data and found a coupling of 0.4 , on average, between sub-canopy and external air temperatures. For temperate ecosystems, we retrieved raw data from a three-year (20122014) time series (Varner and Dearing 2014) and found that the slope parameter of the relationship between sub-canopy and free-air daily maximum temperatures during summer time was about $0.6\left(\mathrm{p}<<0.001 ; \mathrm{R}^{2}=0.86 ; \mathrm{n}=118\right)$. Here we assume that climatic coupling decreases linearly with topographic concavity and canopy density, with the slope parameter between sub-canopy and free-air temperatures being the lowest (set to 0.6) within ravines or gullies with a dense canopy cover (Fig. 2). By simply multiplying this slope value to future free-air temperatures, it is possible to project future sub-canopy temperatures after accounting for local decoupling. Thus, if we consider a $+2^{\circ} \mathrm{C}$ warming scenarios and a locality where sub-canopy temperatures are weakly coupled to free-air temperatures (slope $=0.6)$, then this locality will be only $1.2^{\circ} \mathrm{C}$ warmer.

\section{A greater probability for species to persist locally under climate warming}

Based on the WorldClim grid of synoptic temperatures at $1 \mathrm{~km}$ resolution, $B I O 5$ spanned only $0.4^{\circ} \mathrm{C}\left(23.2-23.6^{\circ} \mathrm{C}\right)$ across the forest of Compiègne (Fig. A1-1 in Supplementary material Appendix A1). Modelling topoclimate at $25 \mathrm{~m}$ resolution (Fig. A2-3 in Supplementary material Appendix A2), it spanned $1.1^{\circ} \mathrm{C}\left(22.7-23.8^{\circ} \mathrm{C}\right)$ and accounting for the buffering capacity due to both physiographic and biophysical processes operating at $50 \mathrm{~cm}$ resolution (Fig. A3-1 in Supplementary material Appendix A3), it spanned up to $3.6^{\circ} \mathrm{C}\left(20.2-23.8^{\circ} \mathrm{C}\right)$. Such a spatially hierarchical downscaling of sub-canopy temperatures allowed the range of temperature conditions available across the forest of Compiègne to increase by $3.2^{\circ} \mathrm{C}$ toward the cold end of the gradient compared with free-air temperature, thus providing a wider 'safety margin' at the warmest extreme of $P$. virtualis' fundamental niche (Fig. 3). Accounting for the combined effect of climatic buffering and decoupling, the probability for $P$. virtualis to persist locally under a warming scenario of $+2^{\circ} \mathrm{C}$ increased by +0.2 (Student unpaired-sample t-test: $\mathrm{p}<<0.001$; Table 2), on average, compared to a situation based on macroclimatic conditions solely. We note that the probability for $P$. virtualis to persist could locally increase 
Current
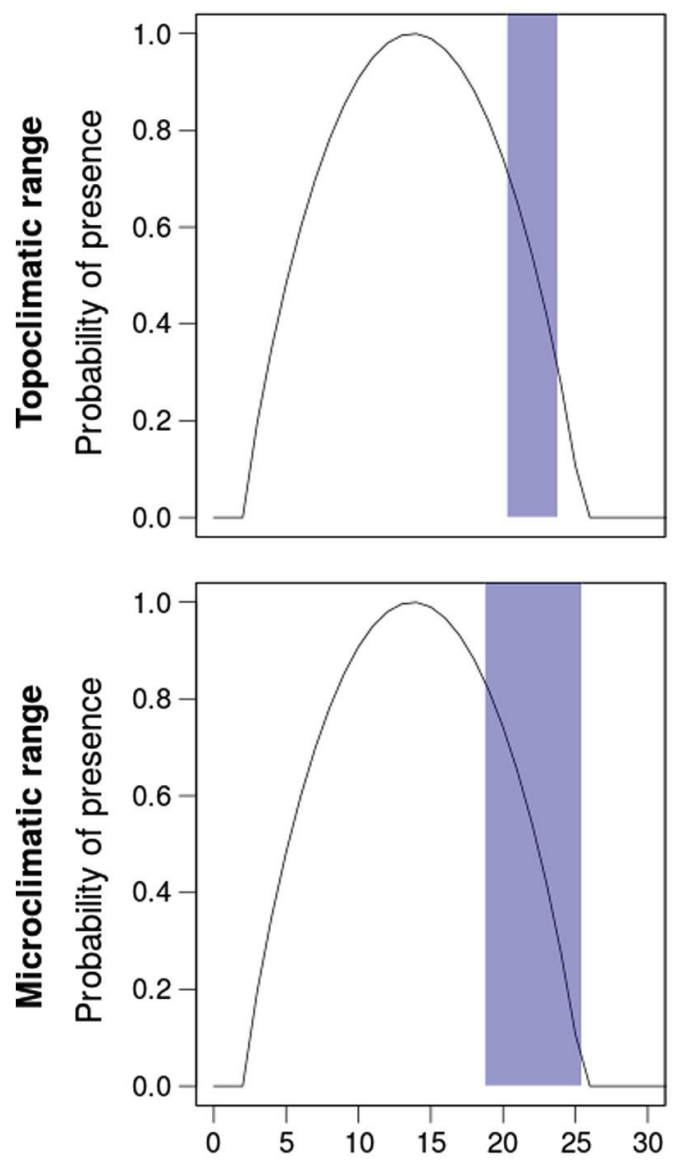

Future
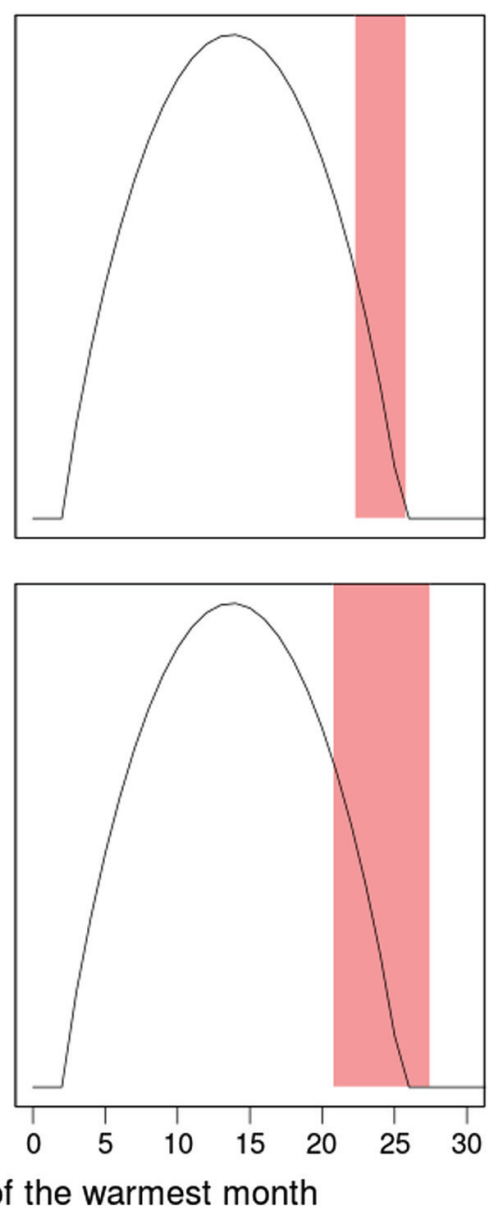

Figure 3. Simulated (cf. Eq. 1 in Supplementary material Appendix A1) response curve of Polystichum virtualis along maximum temperature of the warmest month (BIO5). The blue and red bands represent the range of temperature conditions available across the forest of Compiègne under baseline and warming $\left(+2^{\circ} \mathrm{C}\right)$ conditions, respectively, after accounting for topoclimatic processes at $25 \mathrm{~m}$ resolution (top panels) as well as microclimatic processes (buffering and decoupling effects) at $50 \mathrm{~cm}$ resolution (bottom panels).

by +0.55 thus reaching a maximum probability of occurrence of up to 0.6 (Fig. 4-6) within the forest of Compiègne. Not only the pure effect of the buffering capacity provided by physiographic and habitat features but also the pure effect of its associated local decoupling between sub-canopy and free-air temperatures increased the probability for $P$. virtualis to persist locally under a warming scenario of $+2^{\circ} \mathrm{C}$
(Student unpaired-sample t-test: $\mathrm{p}<<0.001$; Table 2) (Fig. 5). Noteworthy, we also found significant increases in the probability for $P$. virtualis to persist locally when comparing outputs from our microclimatic model - after incorporating the buffering capacity with or without its associated local decoupling - against outputs from the topoclimatic model at $25 \mathrm{~m}$ resolution (Supplementary material Appendix A5).

Table 2. Mean and standard error of the mean (SEM) of the probability of occurrence of Polystichum virtualis across the forest of Compiègne under baseline and warming $\left(+2^{\circ} \mathrm{C}\right)$ conditions at different spatial resolutions. For each spatial resolution corresponds a different set of climatic processes. At $1 \mathrm{~km}$ resolution, climatic conditions represent macroclimate (Macro) or free-air maximum temperature of the warmest month (BIO5). At $25 \mathrm{~m}$ resolution, climatic conditions represent topoclimate (Topo) or free-air BIO5 after accounting for physiographic processes. At $50 \mathrm{~cm}$ resolution, climatic conditions represent microclimate (Micro) or sub-canopy BIO5 after accounting for the buffering (B) capacity due to both topographic concavity and canopy density. In addition to the buffering capacity, the local decoupling (D) between sub-canopy and free-air BIO5 is accounted for when projecting the probability of occurrence of $P$. virtualis under a warming scenario of $+2^{\circ} \mathrm{C}$.

\begin{tabular}{|c|c|c|c|c|c|}
\hline \multirow[b]{2}{*}{ Spatial resolution } & \multirow[b]{2}{*}{ Climatic processes } & \multicolumn{2}{|c|}{ Probability of occurrence (baseline conditions) } & \multicolumn{2}{|c|}{ Probability of occurrence $\left(+2^{\circ} \mathrm{C}\right.$ warming scenario $)$} \\
\hline & & Mean & SEM & Mean & SEM \\
\hline $1 \mathrm{~km}$ & Macro & 0.32 & $\pm 0.4510^{-1}$ & 0.02 & $\pm 0.9010^{-2}$ \\
\hline $25 \mathrm{~m}$ & Topo & 0.38 & $\pm 0.3910^{-4}$ & 0.03 & $\pm 0.5910^{-4}$ \\
\hline $50 \mathrm{~cm}$ & Micro (B) & 0.49 & $\pm 0.2710^{-4}$ & 0.19 & $\pm 0.3910^{-4}$ \\
\hline $50 \mathrm{~cm}$ & Micro (B + D) & - & - & 0.22 & $\pm 0.4610^{-4}$ \\
\hline
\end{tabular}



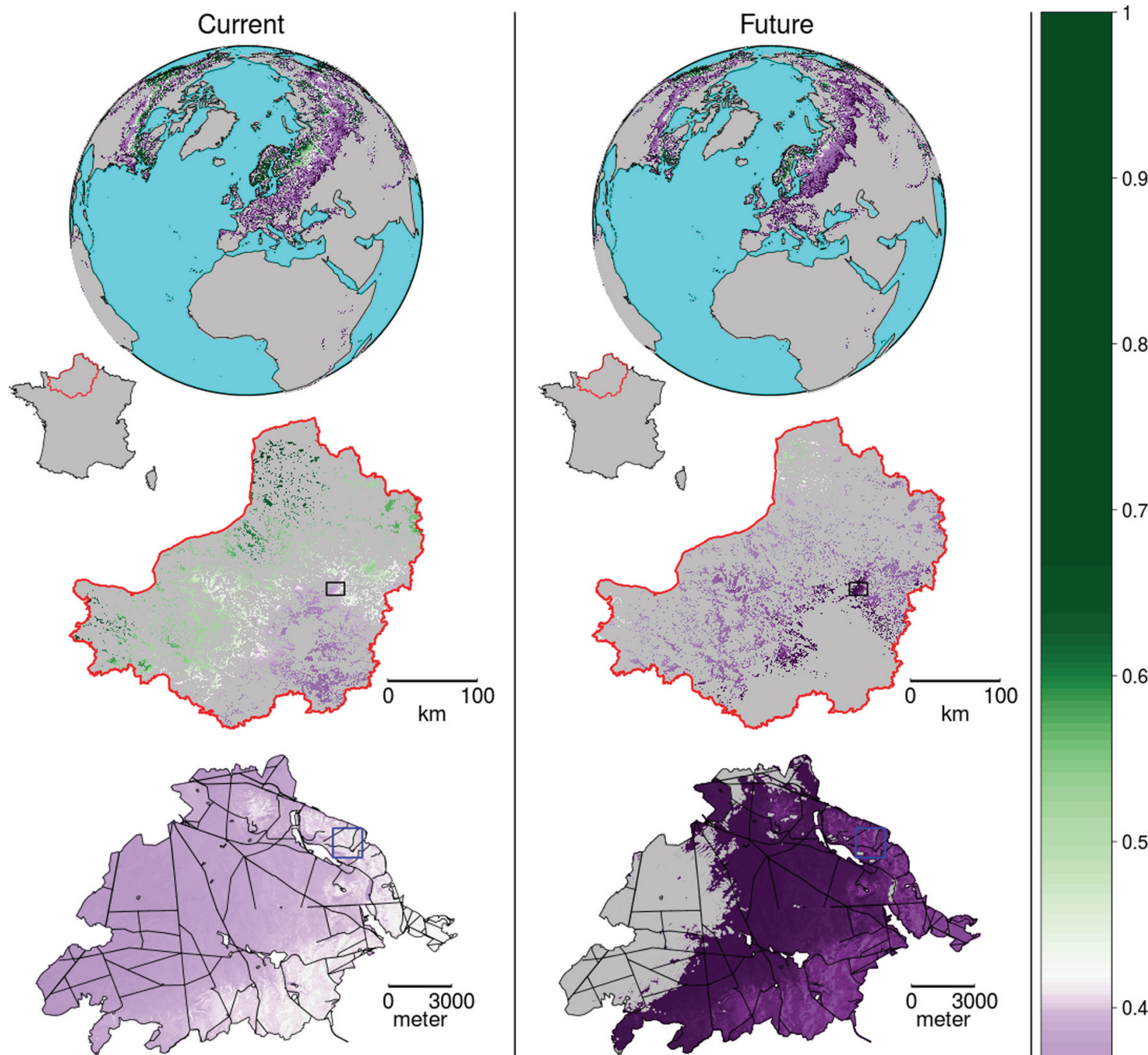

$-0.9$
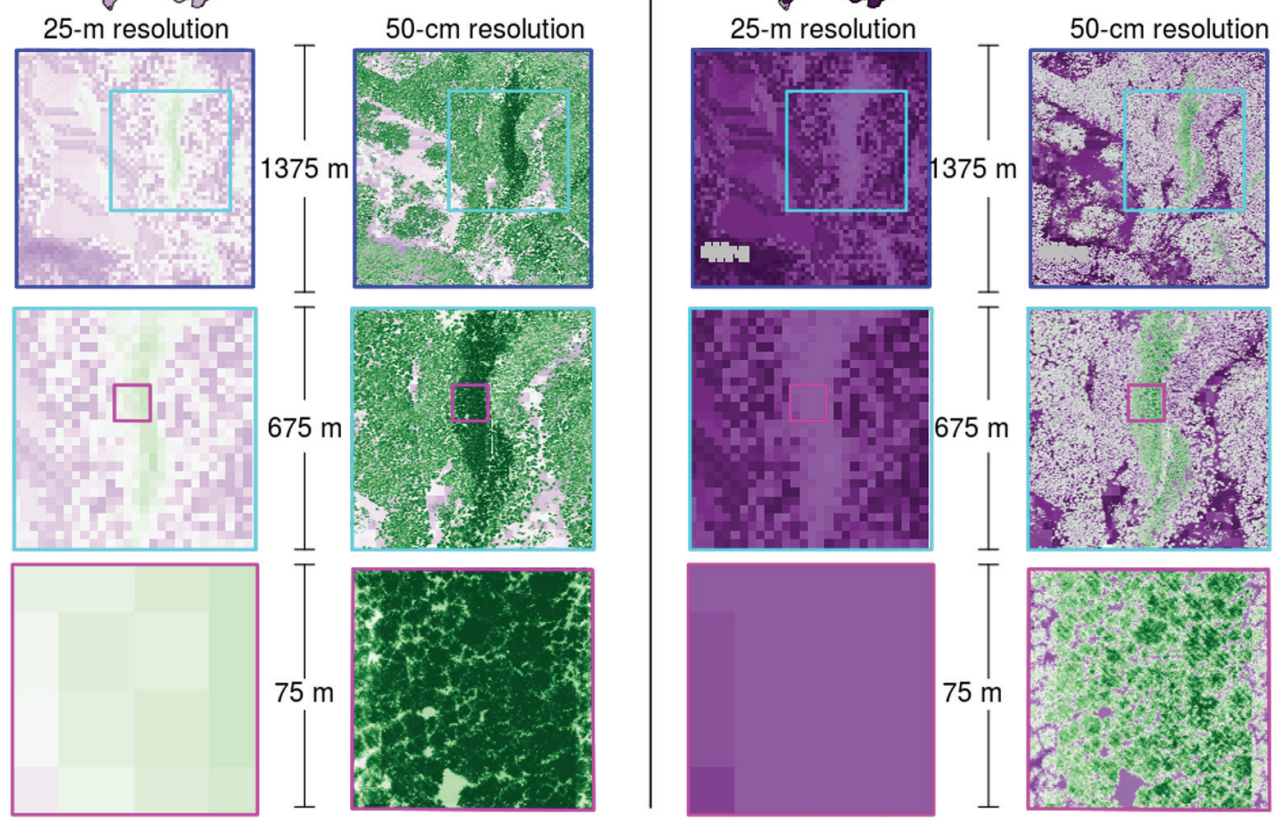

Figure 4. Probability of occurrence of Polystichum virtualis at global (1 km resolution across all continents excluding Antarctica), regional ( $25 \mathrm{~m}$ resolution across northern France) and landscape $(25 \mathrm{~m}$ resolution across the forest of Compiègne) scales and under both baseline (left) and warming $\left(+2^{\circ} \mathrm{C}\right)$ (right) conditions. Three cascading zooming windows within the forest of Compiègne are depicted at both 25 $\mathrm{m}$ resolution (topoclimate only) and $50 \mathrm{~cm}$ resolution (buffering and decoupling effects) to show the cumulative impacts of the buffering capacity and the local decoupling on the probability of occurrence of $P$. virtualis. 


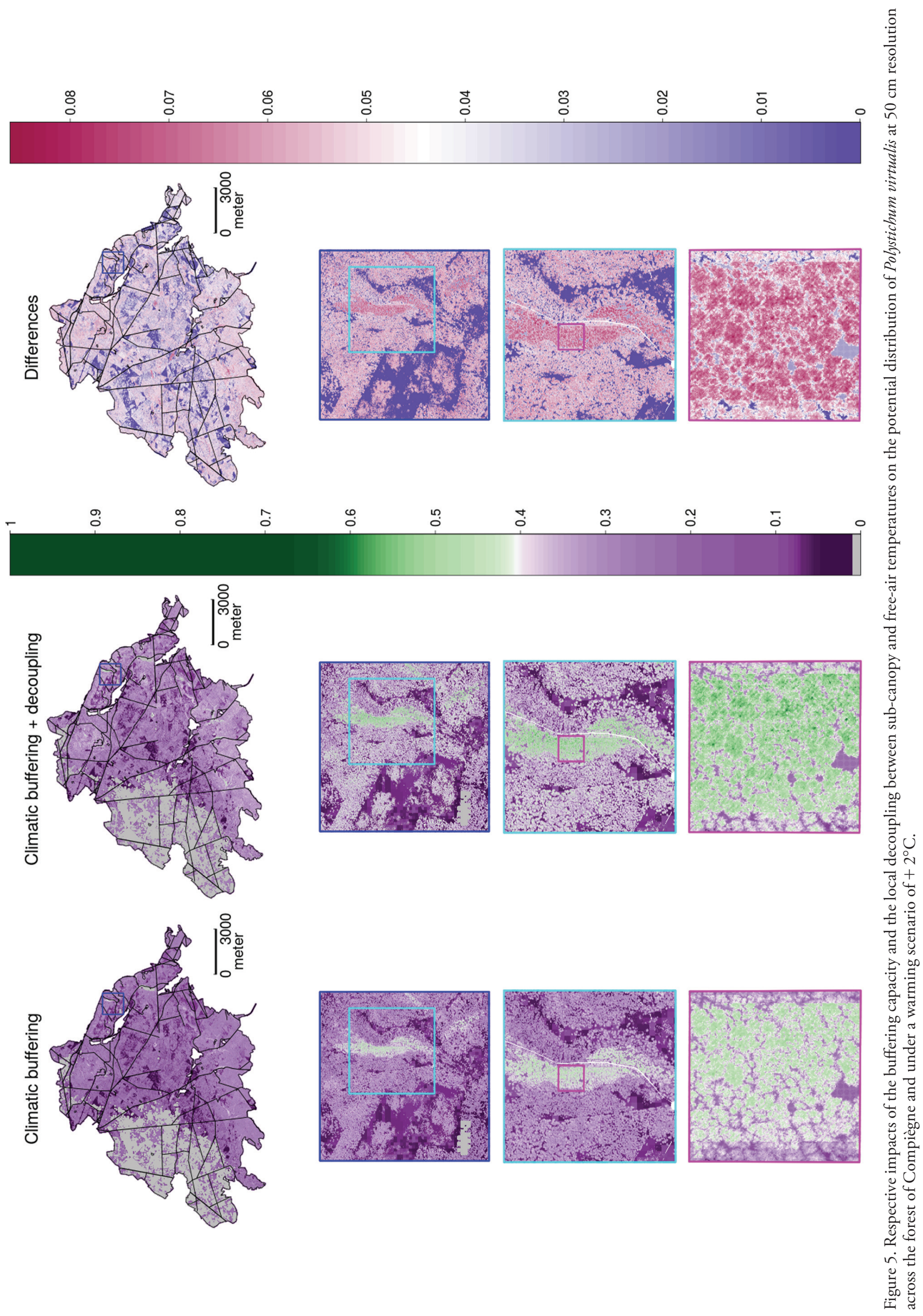




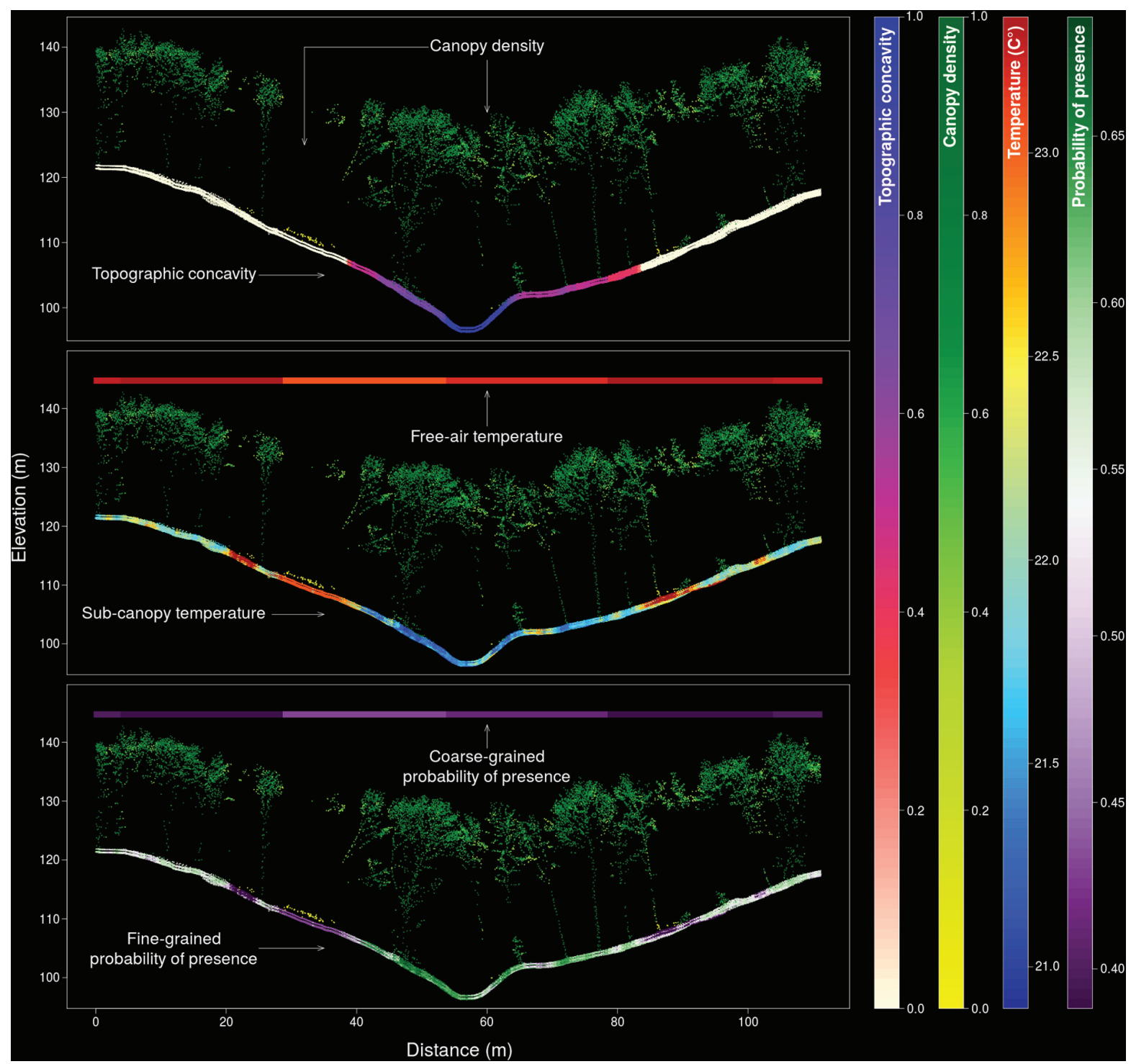

Figure 6. Cross-section in a light detection-and-ranging (LiDAR) point cloud showing the effect of both canopy density and topographic concavity in buffering free-air temperature (i.e. $25 \mathrm{~m}$ resolution layer above the canopy) near the ground (i.e. sub-canopy temperature) and its consequences on the probability of occurrence of Polystichum virtualis. The location of this cross-section is depicted in zooming window no. 3 in Fig. A3-1 in Supplementary material Appendix A3.

\section{A synthesis for effectively considering climatic microrefugia when projecting species redistribution}

Outputs from our spatially hierarchical downscaling framework support and strengthen former attempts to consider the buffering capacity (cf. spatial dynamics) associated with microrefugia when projecting species distribution changes under climate warming (Randin et al. 2009, Dobrowski 2011, Dullinger et al. 2012, Franklin et al. 2013, Slavich et al. 2014). However, we here demonstrate that the buffering and decoupling capacities (cf. spatiotemporal dynamics) due to canopy cover, involving very fine $(<1 \mathrm{~m})$ resolutions, further increases the probability for sub-canopy species to persist locally. This has important implications for species redistribution under anthropogenic climate change. Here we discuss these implications as well as other challenges and provide future directions for effectively modelling potential climatic microrefugia.

\section{Solving the spatial-resolution paradox}

Recent work modelling the spatial dynamics of microclimate at fine $(<30 \mathrm{~m})$ resolutions and assessing the impact on species redistribution under climate warming (Table 1) have all demonstrated that the probability of local species persistence will increase compared with projections based on coarse-grained $(>1 \mathrm{~km})$ climatic grids representing free-air temperature. Similarly, we have shown that the use of finer-resolution $(<1 \mathrm{~m})$ sub-canopy temperature grids accounting for both physiographic and biophysical processes further enlarges the range of available temperature conditions towards the cold end of the gradient and thus provides a safety margin for species to persist locally under climate warming (Fig. 3). The overall take-home message being that projections from coarser-grained correlative species distribution models (SDMs) tend to overestimate extinction risks compared to finer-grained correlative SDMs (Randin et al. 2009). But Trivedi et al. (2008) argued that projections 
from coarse-grained correlative SDMs tend to overestimate species persistence and thus underestimate extinction risks under future climate change. Ironically, none of these two diverging conclusions is wrong. Franklin et al. (2013) have demonstrated that coarser-grained $(4 \mathrm{~km})$, relative to finergrained $(90 \mathrm{~m})$, correlative SDMs, simultaneously overestimate the total amount of regionally suitable habitat but underestimate the presence of locally suitable habitats that could allow species persistence within microrefugia. This spatial-resolution paradox is inherent to correlative SDMs and stems from the spatial resolution of the predictor variables used to model species distribution. The coarser the spatial resolution of the climatic data, the broader the thermal tolerance of a given species' realised niche estimated from a correlative SDM (Harwood et al. 2014). This overestimation of a species' thermal tolerance increases the possibilities for that species to occur within a suitable habitat at the regional scale and thus to regionally persist under future climate change (Trivedi et al. 2008). As a compensatory effect, the use of free-air temperature grids at coarse spatial resolutions increases the probability to overlook opportunities for local persistence due to suitable microclimatic conditions (Franklin et al. 2013).

Although the use of mechanistic SDMs (Kearney and Porter 2009) may partly solve this paradox by relying on a fixed species' response curve (cf. the physiological response is known as it is the case for P. virtualis) that is independent from the spatial resolution of the climatic variables, projections will still depend on the spatial resolution of the predictors. To avoid that issue, it has been recommended to use climatic grids at a spatial resolution matching the size of the studied organism (Potter et al. 2013). Accordingly, the recent literature has proposed solutions to generate correlative or mechanistic SDMs based on fine-grained temperature data representing in-situ temperature conditions better matching the size of the studied organisms (Bennie et al. 2013, Pradervand et al. 2014). These recent scientific advances usually combine in-situ environmental measurements from fine-grained microsensor networks with predictor variables derived from very high-resolution remote sensing data (e.g. airborne LiDAR and hyperspectral images) to interpolate microclimate (Table 1). Interestingly, our downscaling framework only requires very high-resolution remote sensing data without the need of spatially interpolating microclimate from a large network of microsensors. Although more data on microclimate is needed to better assess the buffering capacity provided by physiographic and biophysical features (Fig. 2), our framework shows that the scientific knowledge readily available from the literature on the magnitude of the this buffering capacity (Supplementary material Appendix A4) can be used to model microclimate at a spatial resolution that match organism size.

\section{Gathering long-term time series of microclimatic data}

Not only the spatial resolution of the predictor variables matters for capturing the buffering capacity of microrefugia but long-term time series on microclimate are needed too for accurately assessing the local decoupling between in-situ and free-air temperatures. Besides, the sustainability of this decoupling also matters for the long-term survival of populations under deteriorating climatic conditions. As demonstrated throughout our framework, this important feature that defines the temporal dynamic of microrefugia clearly increases the probability of species persistence and thus delays the risk of extirpation under climate warming by means of microclimatic inertia. Caution is therefore required when interpreting extinction risks from species redistribution projections that do not incorporate the potential decoupling between in-situ and free-air temperatures. Stratifying permanent microsensors across small and large spatial extents simultaneously to capture the spatiotemporal variability of both in-situ and free-air temperatures will help to better assess the long-term relationship between in-situ and free-air temperatures (Fridley 2009, Dobrowski et al. 2009, Hylander et al. 2015, Locosselli et al. 2016) representing the strength of the coupling (Locosselli et al. 2016). Setting up such a spatially hierarchical network of microsensors encompassing not only a wide range of topographic complexities but also the full range of canopy cover from open to closed conditions is timely to test the relationship between in-situ temperatures and canopy density or topographic concavity (cf. Fig. 2). Finally, we need permanent networks to monitor the sustainability of the decoupling between in-situ and free-air temperatures and thus the refugial capacity of a potential microrefugium.

\section{Modelling the vertical temperature profile near the ground surface}

Although our spatially hierarchical downscaling framework focuses on the horizontal resolution of microclimate solely, it can also be adjusted to account for the vertical distribution of microclimate (Dingman et al. 2013). Contrary to weather stations measuring synoptic temperature conditions at $2 \mathrm{~m}$ height, microsensors have been used in the scientific literature to capture microclimate near the ground where biologically important processes, such as plant establishment, are being mediated (Potter et al. 2013). The maximum buffering effect $\left(-3^{\circ} \mathrm{C}\right)$ we used in our framework is actually a mean across several studies that measured sub-canopy temperature at different heights, ranging between $0-2.5 \mathrm{~m}($ mean $=1.4 \mathrm{~m})($ see Table A4-1 in Supplementary material Appendix A4). Depending on the size of the organism under study, one may adjust the magnitude of this buffering effect by modelling its vertical profile near the ground surface (Kearney et al. 2014). For instance, Dingman et al. (2013) have modelled maximum temperature at several heights between 0.05-4.00 $\mathrm{m}$ by using a downscaled climate model coupled with a network of temperature sensors capturing the vertical temperature profile near the ground surface. Interestingly, the recruitment pattern of black oak Quercus kelloggii seedlings was better explained by maximum temperature at the ground surface than maximum temperature at $2 \mathrm{~m}$ height (Dingman et al. 2013). Hence, even for large species like trees, microclimate near the ground surface matters for seedling establishment and recruitment (Dingman et al. 2013, Serra-Diaz et al. 2015). By integrating the vertical temperature profile near the ground surface in our framework, one may effectively model microclimate for different life stages of a given species. 


\section{Incorporating temperature-moisture interactions}

We focused on a single limiting bioclimatic variable (BIO5) to illustrate our framework, but the buffering capacity of microrefugia may also be determined by other important bioclimatic variables such as moisture-related variables. It has long been recognized that moisture in the air and soil reduces the temporal variability of air and soil temperatures (Bennie et al. 2008, Ashcroft and Gollan 2013). For instance, Ashcroft and Gollan (2013) have found that the diurnal range of air temperature was reduced under moist conditions whereas it increased under drier conditions, suggesting that moisture interacts with air temperature to amplify the buffering and decoupling capacities associated with microrefugia. Based on these findings, ravine forests maintaining moist conditions due to both a concave topography and a dense canopy are likely to be even more buffered from exterior temperature fluctuations than what we initially assumed in our framework, which does not account for temperature-moisture interactions.

Beyond the effects of topography and tree canopy, soil characteristics (e.g. water holding capacity) also play important roles in locally regulating moisture availability and thus the buffering capacity of microrefugia. Recently, downscaled climate models coupled with deterministic hydrological models that account for relative humidity and soil water holding capacity (Stephenson 1998) to model climatic water deficit have been proposed (Flint and Flint 2012). Using this hybrid approach integrating temperature-moisture interactions, McCullough et al. (2016) have identified potential microrefugia in the lowlands of the Sierra Nevada region. Incorporating moisture-related variables and their potential interactions with temperature into our spatially hierarchical downscaling framework is an important future direction for effectively capturing microrefugia dynamics.

\section{Accounting for the labile nature of tree canopy}

The main limitation of our framework is the explicit consideration of canopy density as static under anthropogenic climate change. Yet, climate change is likely to affect not only the seasonality of canopy dynamics via defoliations during the winter season for temperate deciduous forests but also inter-annual variations in canopy density due to climate-driven changes in anthropogenic (e.g. thinning and clear-cut) and natural disturbances (e.g. windthrow and drought). These intra- and inter-annual variations in canopy density will in turn affect how microclimates and potential microrefugia are spatially structured (Serra-Diaz et al. 2015). Not only will these fluctuations in canopy density affect the buffering effect but also the decoupling capacity of forests. For instance, clear-cuts may temporarily hamper both the buffering effect due to canopy cover but also the decoupling between in-situ and free-air temperatures thus limiting the refugial capacity of forests. Here, we illustrated our framework by focusing on the buffering and decoupling effects of canopy cover during the warmest period of the year. However, the exact same approach can be used to account for the buffering and decoupling effects of canopy cover that usually increases and stabilizes minimum air temperature during the coldest period of the year (Joly 2014, Varner and Dearing 2014). Besides, one can use canopy density to account for snowpack duration and distribution in mountainous regions
(Storck et al. 2002), which in turn influences microclimates and thus the refugial capacity of mountain forests. It is thus possible to account for the seasonality of the buffering and decoupling effects due to canopy cover in species redistribution projections by focusing on both maximum and minimum air temperatures during the warmest and coldest periods of the year, respectively, adjusted by the timing of snowmelt in mountainous regions. Regarding the inter-annual variability in canopy density, recent scientific advances in individual-based forest modelling linking canopy dynamics and shade tolerances (Liénard and Strigul 2016) provide important future directions to incorporate the labile nature of tree canopy in our framework.

\section{Mistaking microrefugia dynamics for microevolutionary processes}

Last but not least, species may be buffered from climate change due to enhanced adaptive capacity from genetically rich relict populations improving their probability to persist locally by enlarging their climatic tolerance through microevolutionary adaptation (Hampe and Jump 2011, Reed et al. 2011). This is especially true for populations at the trailing edge of a species' shifting range that are often associated with microrefugia or trailing-edge holdouts (sensu Hannah et al. 2014) but at the same time genetically more diverse than core or leading-edge populations (Hampe and Petit 2005). Hence, any observed buffering/decoupling effect of so-called microrefugia for trailing-edge population might be mistaken for microevolution. To avoid such a confounding effect, it is important to consider long-term metapopulation dynamics. Microrefugial populations usually oscillate between periods of high connectivity with the main population and periods of high isolations from the main population and thus can be considered as long-term variant of metapopulations for which microclimatic stability supersedes gene flow in determining species survival (Mosblech et al. 2011). More research is needed to account for these long-term metapopulation dynamics that may help distinguishing between microrefugia dynamics and microevolutionary processes under future climate change. Although a challenging endeavour and a hot topic in global change ecology, recent advances in SDMs have coupled niche-based models of habitat suitability (cf. traditional correlative or mechanistic SDMs) with either population models (Dullinger et al. 2012) or spatially explicit metapopulation models (Gallien et al. 2010, NaujokaitisLewis et al. 2013). One way forward is thus to combine our spatially hierarchical downscaling framework with such hybrid SDMs that account for demographic processes.

Acknowledgements - We are grateful to the Office National des Forêts (ONF) for providing us with small-footprint LiDAR data across the entire lowland forest of Compiègne. We thank Catherine Graham, Josep M. Serra-Diaz and two anonymous referees for insightful comments on the manuscript. JL and GP acknowledge a grant (APR 2014) from the SFR Condorcet FR CNRS 3417 for the project entitled 'Les ravins boisés en milieux de grandes cultures' (CREUSE).

\section{References}

Ashcroft, M. B. and Gollan, J. R. 2012. Fine-resolution (25 m) topoclimatic grids of near-surface $(5 \mathrm{~cm})$ extreme temperatures 
and humidities across various habitats in a large $(200 \times 300$ $\mathrm{km}$ ) and diverse region. - Int. J. Climatol. 32: 2134-2148.

Ashcroft, M. B. and Gollan, J. R. 2013. Moisture, thermal inertia, and the spatial distributions of near-surface soil and air temperatures: understanding factors that promote microrefugia. - Agricult. For. Meteorol. 176: 77-89.

Ashcroft, M. B. et al. 2008. The effect of exposure on landscape scale soil surface temperatures and species distribution models. - Landscape. Ecol. 23: 211-225.

Ashcroft, M. B. et al. 2012. A novel approach to quantify and locate potential microrefugia using topoclimate, climate stability, and isolation from the matrix. - Global Change Biol. 18: 1866-1879.

Barnosky, A. D. et al. 2011. Has the earth's sixth mass extinction already arrived? - Nature 471: 51-57.

Barry, R. G. 1992. Mountain weather and climate. - Routledge.

Bennie, J. et al. 2008. Slope, aspect and climate: spatially explicit and implicit models of topographic microclimate in chalk grassland. - Ecol. Modell. 216: 47-59.

Bennie, J. et al. 2013. Range expansion through fragmented landscapes under a variable climate. - Ecol. Lett. 16: 921-929.

Bertrand, R. et al. 2011. Changes in plant community composition lag behind climate warming in lowland forests. - Nature 479: 517-520.

Bertrand, R. et al. 2016. Ecological constraints increase the climatic debt in forests. - Nat. Commun. 7: 12643.

Chen, J. et al. 1999. Microclimate in forest ecosystem and landscape ecology variations in local climate can be used to monitor and compare the effects of different management regimes. - BioScience 49: 288-297.

Davis, M. B. and Shaw, R. G. 2001. Range shifts and adaptive responses to Quaternary climate change. - Science 292: 673-679.

De Frenne, P. et al. 2013. Microclimate moderates plant responses to macroclimate warming. - Proc. Natl Acad. Sci. USA 110: 18561-18565.

Dingman, J. R. et al. 2013. Cross-scale modeling of surface temperature and tree seedling establishment in mountain landscapes. - Ecol. Process. 2: 30.

Distler, T. et al. 2015. Stacked species distribution models and macroecological models provide congruent projections of avian species richness under climate change. $-\mathrm{J}$. Biogeogr. 42 : 976-988.

Dobrowski, S. Z. 2011. A climatic basis for microrefugia: the influence of terrain on climate. - Global Change Biol. 17: 1022-1035.

Dobrowski, S. Z. et al. 2009. How much influence does landscapescale physiography have on air temperature in a mountain environment? - Agricult. For. Meteorol. 149: 1751-1758.

Dullinger, S. et al. 2012. Extinction debt of high-mountain plants under twenty-first-century climate change. - Nat. Clim. Change 2: 619-622.

Ewers, R. M. and Banks-Leite, C. 2013. Fragmentation impairs the microclimate buffering effect of tropical forests. - PLoS ONE 8: e58093.

Flint, L. E. and Flint, A. L. 2012. Downscaling future climate scenarios to fine scales for hydrologic and ecological modeling and analysis. - Ecol. Process. 1: 2.

Fotheringham, A. S. et al. 2002. Geographically weighted regression: the analysis of spatially varying relationships. - Wiley-Blackwell.

Franklin, J. et al. 2013. Modeling plant species distributions under future climates: how fine scale do climate projections need to be? - Glob. Change Biol. 19: 473-483.

Frey, S. J. K. et al. 2016. Spatial models reveal the microclimatic buffering capacity of old-growth forests. - Sci. Adv. 2: e1501392.

Fridley, J. D. 2009. Downscaling climate over complex terrain: high finescale $(<1000 \mathrm{~m})$ spatial variation of near-ground temperatures in a montane forested landscape (Great Smoky

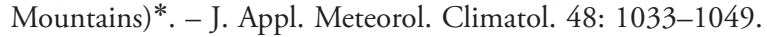

Gallien, L. et al. 2010. Predicting potential distributions of invasive species: where to go from here? - Divers. Distrib. 16: 331-342.

Geiger, R. 1950. The climate near the ground. - Harvard Univ. Press.

Gollan, J. R. et al. 2014. Assessing the distribution and protection status of two types of cool environment to facilitate their conservation under climate change. - Conserv. Biol. 28: 456-466.

Grimmond, C. S. B. et al. 2000. Spatial variability of micro-climatic conditions within a mid-latitude deciduous forest. - Clim. Res. 15: 137-149.

Grotch, S. L. and MacCracken, M. C. 1991. The use of general circulation models to predict regional climatic change. - J. Clim. 4: 286-303.

Hampe, A. and Petit, R. J. 2005. Conserving biodiversity under climate change: the rear edge matters. - Ecol. Lett. 8: 461-467.

Hampe, A. and Jump, A. S. 2011. Climate relicts: past, present, future. - Annu. Rev. Ecol. Evol. Syst. 42: 313-333.

Hannah, L. et al. 2014. Fine-grain modeling of species' response to climate change: holdouts, stepping-stones, and microrefugia. - Trends Ecol. Evol. 29: 390-397.

Harwood, T. D. et al. 2014. Microclimate is integral to the modeling of plant responses to macroclimate. - Proc. Natl Acad. Sci. USA 111: E1164-E1165.

Heller, N. E. et al. 2015. Targeting climate diversity in conservation planning to build resilience to climate change. - Ecosphere 6: $1-20$.

Hijmans, R. J. et al. 2005. Very high resolution interpolated climate surfaces for global land areas. - Int. J. Climatol. 25: 1965-1978.

Hylander, K. et al. 2015. Microrefugia: not for everyone. - Ambio 44: 60-68.

Joly, D. 2014. Etude comparative de la température en forêt et en espace ouvert dans le parc naturel régional du Haut-Jura. - Climatologie 11: 19-33.

Kearney, M. and Porter, W. 2009. Mechanistic niche modelling: combining physiological and spatial data to predict species' ranges. - Ecol. Lett. 12: 334-350.

Kearney, M. R. et al. 2014. Microclim: global estimates of hourly microclimate based on long-term monthly climate averages. - Sci. Data 1: 140006.

Keppel, G. and Wardell-Johnson, G. W. 2015. Refugial capacity defines holdouts, microrefugia and stepping-stones: a response to Hannah et al. - Trends Ecol. Evol. 30: 233-234.

Keppel, G. et al. 2012. Refugia: identifying and understanding safe havens for biodiversity under climate change. - Glob. Ecol. Biogeogr. 21: 393-404.

Keppel, G. et al. 2015. The capacity of refugia for conservation planning under climate change. - Front. Ecol. Environ. 13: $106-112$.

Leal, M. E. 2001. Microrefugia, small scale ice age forest remnants. - Syst. Geogr. Plants 71: 1073-1077.

Lefsky, M. A. et al. 2002. Lidar remote sensing for ecosystem studies. - BioScience 52: 19-30.

Lenoir, J. and Svenning, J.-C. 2013. Latitudinal and elevational range shifts under contemporary climate change. - In: Levin, S. A. (ed.), Encyclopedia of biodiversity (2nd ed.). Academic Press, pp. 599-611.

Lenoir, J. and Svenning, J.-C. 2015. Climate-related range shifts - a global multidimensional synthesis and new research directions. - Ecography 38: 15-28.

Lenoir, J. et al. 2008. A significant upward shift in plant species optimum elevation during the 20th Century. - Science 320: 1768-1771. 
Lenoir, J. et al. 2013. Local temperatures inferred from plant communities suggest strong spatial buffering of climate warming across northern Europe. - Global Change Biol. 19: $1470-1481$.

$\mathrm{Li}, \mathrm{S}$. et al. 2010. Investigating spatial non-stationary and scaledependent relationships between urban surface temperature and environmental factors using geographically weighted regression. - Environ. Model. Softw. 25: 1789-1800.

Liénard, J. and Strigul, N. 2016. An individual-based forest model links canopy dynamics and shade tolerances along a soil moisture gradient. - Open Sci. 3: 150589.

Locosselli, G. M. et al. 2016. Rock outcrops reduce temperatureinduced stress for tropical conifer by decoupling regional climate in the semiarid environment. - Int. J. Biometeorol. 60: 639-649.

McCullough, I. M. et al. 2016. High and dry: high elevations disproportionately exposed to regional climate change in Mediterranean-climate landscapes. - Landscape Ecol. 31: 1063-1075.

Miró Pérez, J. J. et al. 2015. Statistical downscaling and attribution of air temperature change patterns in the Valencia region (1948-2011). - Atmospheric Res. 156: 189-212.

Mosblech, N. A. S. et al. 2011. On metapopulations and microrefugia: palaeoecological insights. - J. Biogeogr. 38: 419-429.

Naujokaitis-Lewis, I. R. et al. 2013. Uncertainties in coupled species distribution-metapopulation dynamics models for risk assessments under climate change. - Divers. Distrib. 19: 541-554.

Parducci, L. et al. 2012. Glacial survival of boreal trees in northern Scandinavia. - Science 335: 1083-1086.

Pepin, N. C. and Seidel, D. J. 2005. A global comparison of surface and free-air temperatures at high elevations. - J. Geophys. Res. Atmospheres 110: D03104.

Pepin, N. C. et al. 2011. The influence of surface versus free-air decoupling on temperature trend patterns in the western United States. - J. Geophys. Res. Atmospheres 116: D10109.

Porfirio, L. L. et al. 2014. Improving the use of species distribution models in conservation planning and management under climate change. - PLoS ONE 9: e113749.

Potter, K. A. et al. 2013. Microclimatic challenges in global change biology. - Glob. Change Biol. 19: 2932-2939.

Pradervand, J.-N. et al. 2014. Very high resolution environmental predictors in species distribution models: moving beyond topography? - Prog. Phys. Geogr. 38: 79-96.

Randin, C. F. et al. 2009. Climate change and plant distribution: local models predict high-elevation persistence. - Global Change Biol. 15: 1557-1569.

Reed, T. E. et al. 2011. Interacting effects of phenotypic plasticity and evolution on population persistence in a changing climate. - Conserv. Biol. 25: 56-63.

Renaud, V. and Rebetez, M. 2009. Comparison between open-site and below-canopy climatic conditions in Switzerland during the exceptionally hot summer of 2003. - Agricult. For. Meteorol. 149: 873-880.

Rödder, D. et al. 2009. Alien invasive slider turtle in unpredicted habitat: a matter of niche shift or of predictors studied? - PLoS ONE 4: e7843.

Rull, V. 2009. Microrefugia. - J. Biogeogr. 36: 481-484.

Rull, V. 2010. On microrefugia and cryptic refugia. - J. Biogeogr. 37: 1623-1625.

Scheffers, B. R. et al. 2014. Microhabitats in the tropics buffer temperature in a globally coherent manner. - Biol. Lett. 10: 20140819.

Supplementary material (Appendix ECOG-02788 at < http:// www.ecography.org/appendix/ecog-02788>). Appendix 1-5.
Schut, A. G. T. et al. 2014. Rapid characterization of vegetation structure to predict refugia and climate change impacts across a global biodiversity hotspot. - PLOS ONE 9: e82778.

Serra-Diaz, J. M. et al. 2015. Disturbance and climate microrefugia mediate tree range shifts during climate change. - Landscape Ecol. 30: 1039-1053.

Slavich, E. et al. 2014. Topoclimate versus macroclimate: how does climate mapping methodology affect species distribution models and climate change projections? - Divers. Distrib. 20: 952-963.

Stephenson, N. 1998. Actual evapotranspiration and deficit: biologically meaningful correlates of vegetation distribution across spatial scales. - J. Biogeogr. 25: 855-870.

Stewart, J. R. and Lister, A. M. 2001. Cryptic northern refugia and the origins of the modern biota. - Trends Ecol. Evol. 16: 608-613.

Stewart, J. R. et al. 2010. Refugia revisited: individualistic responses of species in space and time. - Proc. R. Soc. B 277: 661-671.

Storck, P. et al. 2002. Measurement of snow interception and canopy effects on snow accumulation and melt in a mountainous maritime climate, Oregon, United States. - Water Resour. Res. 38: 1223.

$\mathrm{Su}, \mathrm{Y}$.-F. et al. 2012. Spatial non-stationarity in the relationships between land cover and surface temperature in an urban heat island and its impacts on thermally sensitive populations. - Landscape Urban Plan. 107: 172-180.

Suggitt, A. J. et al. 2015. Microclimate affects landscape level persistence in the British Lepidoptera. - J. Insect Conserv. 19: 237-253.

Svenning, J.-C. and Sandel, B. 2013. Disequilibrium vegetation dynamics under future climate change. - Am. J. Bot. 100: 1266-1286.

Thapa, G. J. et al. 2016. Assessing climate change impacts on forest ecosystems for landscape-scale spatial planning in Nepal. - Curr. Sci. 110: 345.

Tian, F. et al. 2012. Studies on the relationships between land surface temperature and environmental factors in an inland river catchment based on geographically weighted regression and MODIS Data. - IEEE J. Sel. Top. Appl. Earth Obs. Remote Sens. 5: 687-698.

Trivedi, M. R. et al. 2008. Spatial scale affects bioclimate model projections of climate change impacts on mountain plants. - Global Change Biol. 14: 1089-1103.

Vanwalleghem, T. and Meentemeyer, R. K. 2009. Predicting forest microclimate in heterogeneous landscapes. - Ecosystems 12: 1158-1172.

Varner, J. and Dearing, M. D. 2014. The importance of biologically relevant microclimates in habitat suitability assessments. - PLOS ONE 9: e104648.

Wang, C. et al. 2011. The use of geographically weighted regression for the relationship among extreme climate indices in china, the use of geographically weighted regression for the relationship among extreme climate indices in China. - Math. Probl. Eng. Math. Probl. Eng. 2012, 2012: e369539.

Wasof, S. et al. 2013. Ecological niche shifts of understorey plants along a latitudinal gradient of temperate forests in northwestern Europe. - Glob. Ecol. Biogeogr. 22: 1130-1140.

Wasof, S. et al. 2015. Disjunct populations of European vascular plant species keep the same climatic niches. - Global Ecol. Biogeogr. 24: 1401-1412.

Wilkin, K. M. et al. 2016. Climate change refugia, fire ecology and management. - Forests 7: 77.

$\mathrm{Xu}, \mathrm{M}$. et al. 1997. Temperature and its variability in oak forests in the southeastern Missouri Ozarks. - Clim. Res. 8: 209-223. 